\title{
Synthesis of Mo-based nanostructures from organic-inorganic hybrid with enhanced electrochemical for water splitting
}

\author{
Yong Yang, Xiaobin Xu and Xun Wang*
}

\begin{abstract}
A simple method to fabricate Mo-based nanostructures were developed by the thermal decomposition of $\mathrm{MoO}_{x}$-based organic-inorganic hybrid nanowires. Well-defined Mo-based nanostructures, including $\mathrm{MoO}_{2}$ and $\mathrm{MoO}_{3}$ nanowires, can be prepared by changing the hybrid precursor. More importantly, $\mathrm{Mo}_{2} \mathrm{C} / \mathrm{MoO}_{2}$ heterostructures with porous structure were successfully synthesized under an inert atmosphere. The resultant $\mathrm{Mo}_{2} \mathrm{C} / \mathrm{MoO}_{2}$ heterostructures show enhanced electrocatalytic activity and superior stability for electrochemical hydrogen evolution from water. The enhanced performance might be ascribed to the high electrical conductivity and porous structures with one-dimensional structure. Indeed, our result described here provides a new way to synthesize other Mo-based nanostructures for various applications.
\end{abstract}

\section{INTRODUCTION}

Transition metal compounds are receiving growing interest owing to their wide applications in catalysis, electrochemistry, optoelectronics and energy storage [1-7]. In particular, molybdenum oxides, including $\mathrm{MoO}_{2}$ and $\mathrm{MoO}_{3}$, have been regarded as promising materials in field effect transistors and energy storage. Recently, various molybdenum oxides have been prepared through different methods. Generally speaking, $\mathrm{MoO}_{2}$ can be obtained via the reduction of $\mathrm{MoO}_{3}$ under a $\mathrm{H}_{2}$ atmosphere $[8,9]$. However, few reports focused on the preparation of molybdenum oxide nanostructures from organic-inorganic hybrids. Taking the diphasic structures into consideration, the well-defined organic-inorganic hybrid can be seen as an alternative for the design of novel functional materials.

Electrochemical water splitting to produce hydrogen has become a subject of interest to researchers because hydrogen is regarded as the next generation energy for replacing fossil fuels. High-efficiency electrocatalysts always require high current density at low overpotential [10-12]. Up to now, Pt-based metals are the best hydrogen evolution reaction (HER) catalysts $[13,14]$. While the scarcity and high cost of Pt severely hinder their practical application. Recently, various molybdenum-based compounds, such as $\mathrm{MoS}_{2}, \mathrm{MoSe}_{2}, \mathrm{Mo}_{2} \mathrm{C}$, and $\mathrm{MoP}$, are promising non-noble-metal candidates due to their comparable HER activity to Pt-based catalysts [15-17]. Among them, $\mathrm{Mo}_{2} \mathrm{C}$, as a typical interstitial alloys material, has similar metallic structures and possesses Pt-like catalytic behaviors. The traditional synthesis method usually involves the mix of metals with carbon and subsequent carbonization under high temperature to form $\mathrm{Mo}_{2} \mathrm{C}$ structure, which results in serious aggregation and compromises their performance. Recently, various morphologies of $\mathrm{Mo}_{2} \mathrm{C}$ nanostructure with excellent HER performance have been developed through various methods [18-23]. Sun and coworkers [24] synthesized closely interconnected network of molybdenum phosphide nanostructure with highly efficient electrocatalyst for HER. Tang's group reported that nanoporous $\mathrm{Mo}_{2} \mathrm{C}$ can be obtained by thermal decomposition process under an inert atmosphere, which was used as a very effective electrocatalyst for generating hydrogen from water $[25,26]$. In addition, Sasaki's group demonstrated that small $\mathrm{Mo}_{2} \mathrm{C}$ nanoparticles loaded on carbon nanotubes showed highly active and durable electrocatalyst for HER [27]. Evidently, these results suggest that $\mathrm{Mo}_{2} \mathrm{C}$ can be used as an effective electrocatalyst for water splitting.

Recently, the formation of $\mathrm{MoO}_{2}$ with carbon materials such as graphene was used to further improve the performance of $\mathrm{MoO}_{2}$ [28-31]. For example, Mai's group [32] synthesized ultrathin $\mathrm{MoO}_{2}$ nanosheets encapsulated carbon matrix with a facile thermal reduction method, which showed high specific capacities and enhanced cycling stability. $\mathrm{Li}$ and co-workers [33] fabricated flawed $\mathrm{MoO}_{2}$ nanobelts on graphene with enhanced HER performance. However, few reports focus on constructing heterocomposite $\mathrm{Mo}_{2} \mathrm{C}$ with $\mathrm{MoO}_{2}$. Compared with those of the corresponding homogeneous materials, these heterostructured 
nanomaterials usually show enhanced performance, which can be attributed to their specific integrated multifunctionality between binary or ternary nanomaterials [34-39]. Moreover, $\mathrm{Mo}_{2} \mathrm{C}$ possesses excellent structural stability and electronic conductivity because of its high specific conductance. For instance, Wang and co-workers [40] synthesized $\mathrm{MoO}_{2} / \mathrm{Mo}_{2} \mathrm{C}$ heteronanotubes by using mesoporpous carbon CMK-3 as both the template and the reactant. Owing to the high electronic conductivity and stability of $\mathrm{Mo}_{2} \mathrm{C}$, the obtained heteronanotubes exhibited high-performance in lithium-ion batteries. Therefore, it is necessary to develop novel Mo-based nanostructures and explore their application in energy storage and catalytic fields.

In this paper, we present a simple strategy toward Mobased nanostructures derived from organic-inorganic hybrid materials through a simple annealing method. The organic-inorganic hybrid precursor can be converted into various structures by thermal decomposition under different atmosphere. More importantly, a network of interconnected $\mathrm{Mo}_{2} \mathrm{C} / \mathrm{MoO}_{2}$ heterostructures can be successfully synthesized through the same process. Benefiting from the enriched nanoporosity and large surface areas, the resultant $\mathrm{Mo}_{2} \mathrm{C} / \mathrm{MoO}_{2}$ heterostructures shows enhanced electrocatalytic activity for HER. The performance might be ascribed to the high electrical conductivity and unique porous structures. Our results described here may provide a novel method to synthesize other functional Mo-based nanostructures for various applications.

\section{EXPERIMENTAL METHODS}

\section{Synthesis}

\section{Chemicals}

All chemicals were purchased from Sinopharm Chemical Reagent Beijing Company and were used as received without further purification. Deionized water was used throughout the experiment.

\section{Synthesis of organic-inorganic hybrid nanowires}

The $\mathrm{MoO}_{x}$-based organic-inorganic hybrid nanowires were synthesized using a wet chemistry method described previously [41]. For the synthesis of $\mathrm{Mo}_{3} \mathrm{O}_{10}\left(\mathrm{C}_{2} \mathrm{H}_{10} \mathrm{~N}_{2}\right)$ nanowires, $1.24 \mathrm{~g}$ of ammonium heptamolybdate was dissolved in $15 \mathrm{~mL}$ of water, and then $0.8 \mathrm{~g}$ of ethylenediamine was added dropwise, with magnetic stirring at room temperature. A white precipitate was obtained at $\mathrm{pH} 4-5$ under stirring for another $2 \mathrm{~h}$. The product was filtered, washed with ethanol and then freeze-dried for next step. For $\mathrm{Mo}_{3} \mathrm{O}_{10}\left(\mathrm{C}_{6} \mathrm{H}_{8} \mathrm{~N}\right)_{2} \cdot 2 \mathrm{H}_{2} \mathrm{O}$ nanowires, $1.24 \mathrm{~g}$ of ammonium heptamolybdate dissolved in $20 \mathrm{~mL}$ of water, and 1.67 g of aniline were used for the synthesis following the same procedure as above.

\section{Preparation of $\mathrm{MoO}_{2}$ nanowires}

The as-synthesized $\mathrm{Mo}_{3} \mathrm{O}_{10}\left(\mathrm{C}_{2} \mathrm{H}_{10} \mathrm{~N}_{2}\right)$ nanowires were placed into a horizontal furnace and heated to $600^{\circ} \mathrm{C}$ for $2 \mathrm{~h}$ with a heat rate of $2.5^{\circ} \mathrm{C} \mathrm{min}^{-1}$ under $\mathrm{Ar}$ atmosphere, followed by cooling to room temperature.

\section{Preparation of $\mathrm{Mo}_{2} \mathrm{C} / \mathrm{MoO}_{2}$ heterostructures}

$\mathrm{Mo}_{2} \mathrm{C} / \mathrm{MoO}_{2}$ heterostructures were synthesized by the thermal decomposition of $\mathrm{Mo}_{3} \mathrm{O}_{10}\left(\mathrm{C}_{6} \mathrm{H}_{8} \mathrm{~N}\right)_{2} \cdot 2 \mathrm{H}_{2} \mathrm{O}$ nanowires under $\mathrm{N}_{2}$ atmosphere. The as-synthesized samples were placed into a horizontal furnace and heated to $750^{\circ} \mathrm{C}$ for $5 \mathrm{~h}$ with a heat rate of $2.5^{\circ} \mathrm{C} \mathrm{min}^{-1}$, followed by cooling to room temperature.

\section{Preparation of $\mathrm{MoO}_{3}$ nanowires}

The as-synthesized $\mathrm{Mo}_{3} \mathrm{O}_{10}\left(\mathrm{C}_{6} \mathrm{H}_{8} \mathrm{~N}\right)_{2} \cdot 2 \mathrm{H}_{2} \mathrm{O}$ nanowires were placed into a horizontal furnace and heated to $500^{\circ} \mathrm{C}$ in air for $2 \mathrm{~h}$ with a heat rate of $2.5^{\circ} \mathrm{C} \mathrm{min}^{-1}$, followed by cooling to room temperature.

\section{Electrochemical measurements}

The electrochemical measurements were conducted using an electrochemical workstation (CHI660E) in a typical three-electrode setup with an electrolyte solution of $0.5 \mathrm{~mol} \mathrm{~L}^{-1} \mathrm{H}_{2} \mathrm{SO}_{4}$, graphite rod as the counter electrode, and a saturated calomel electrode (SCE) as the reference electrode. Typically, $5 \mathrm{mg}$ of catalyst and $50 \mu \mathrm{L}$ of Nafion solution (5 wt.\%) were dispersed in $1 \mathrm{~mL}$ water-ethanol solution (1:3) by sonicating for $1 \mathrm{~h}$ to form a homogeneous ink. Then $10 \mu \mathrm{L}$ of the catalyst ink was loaded onto a glassy carbon electrode of $5 \mathrm{~mm}$ in diameter. Linear sweep voltammetry (LS) was conducted in $0.5 \mathrm{~mol} \mathrm{~L}^{-1} \mathrm{H}_{2} \mathrm{SO}_{4}$ with a scan rate of $5 \mathrm{mV} \mathrm{s}^{-1}$. Prior to the measurement, a resistance test was made and the $\mathrm{iR}$ compensation was applied by using the CHI software. Electrochemical impedance spectroscopy (EIS) measurements were also carried out in the frequency range of $100 \mathrm{kHz}-0.1 \mathrm{~Hz}$. In all measurements, the SCE reference electrode was calibrated with respect to reversible hydrogen electrode (RHE). RHE calibration was performed according to reported method. In $0.5 \mathrm{~mol} \mathrm{~L}^{-1}$ $\mathrm{H}_{2} \mathrm{SO}_{4}, E(\mathrm{RHE})=E(\mathrm{SCE})+0.281 \mathrm{~V}$.

\section{Characterizations}

The morphology and size of the samples were characterized by a HITACHI H-7700 TEM with an accelerating voltage of $100 \mathrm{kV}$, and an FEI Tecnai G2 F20 S-Twin high-resolution transmission electron microscope (HRTEM) 
equipped with energy dispersive spectrometer (EDS) analyses at $200 \mathrm{kV}$. The scanning electron microscope (SEM) was performed on an LEO 1530. The crystal structure was determined by X-ray diffraction (XRD) on a Rigaku D/ max-2400 X-ray diffractometer using CuKa radiation $(\lambda=$ $1.5418 \AA$ ) at $40 \mathrm{kV}$ voltage and a $40 \mathrm{~mA}$ current ranging from $10^{\circ}$ to $80^{\circ}$. X-ray photoelectron spectroscopy (XPS) experiments were carried out on scanning X-ray microprobe (Quantera SXM, ULVAC-PHI. INC) operated at $250 \mathrm{kV}$, $55 \mathrm{eV}$ with monochromated Al Ka radiation. Brunauer-Emmett-Teller (BET) and pore size of the products were tested using a Quadrasorb SI-MP instrument.

\section{RESULTS AND DISCUSSION}

The synthesis of Mo-based nanostructures involves the synthesis of $\mathrm{MoO}_{x}$-based organic-inorganic hybrid nanowires, followed by annealing treatment of organic-inorganic hybrid precursor in an inert atmosphere. First, $\mathrm{Mo}_{3} \mathrm{O}_{10}\left(\mathrm{C}_{2} \mathrm{H}_{10} \mathrm{~N}_{2}\right)$ nanowires were prepared by one-pot wet chemistry method reported in the literature [41]. The structure and morphology of the product were characterized by XRD and SEM (Supplementary information, Fig. S1). After freeze-dried, an annealing treatment at $600^{\circ} \mathrm{C}$ in $\mathrm{Ar}$ atmosphere with a ramping rate of $2^{\circ} \mathrm{C} \min ^{-1}$ is utilized to convert the $\mathrm{MoO}_{x}$-based organic-inorganic hybrid nanowires into $\mathrm{MoO}_{2}$ nanowires. As shown in Fig. 1a, all of the diffraction peaks can be well assigned to the monoclinic $\mathrm{MoO}_{2}$ (JCPDS 32-0671, space group: $P 21 / n$ ). The morphology of the prepared $\mathrm{MoO}_{2}$ nanowires was further examined by field-emission SEM (FESEM) and TEM, as shown in Figs $1 b$ and c. Both SEM and TEM images show one-dimensional structure with several microns in length and $50-100 \mathrm{~nm}$ in width. A representative high-resolution HRTEM image is shown in Fig. 1d, and the (-111) lattice spacing $(0.343 \mathrm{~nm})$ of $\mathrm{MoO}_{2}$ phase can be clearly observed.

More interestingly, other Mo-based nanostructures can also be obtained by changing the organic-inorganic hybrid precursors. For example, the as-prepared $\mathrm{Mo}_{3} \mathrm{O}_{10}\left(\mathrm{C}_{6} \mathrm{H}_{8} \mathrm{~N}\right)_{2} \cdot 2 \mathrm{H}_{2} \mathrm{O}$ nanowires (Fig. S2) are transformed into $\mathrm{Mo}_{2} \mathrm{C} / \mathrm{MoO}_{2}$ heteronanowires by annealing in $\mathrm{N}_{2}$. $\mathrm{Mo}_{3} \mathrm{O}_{10}\left(\mathrm{C}_{6} \mathrm{H}_{8} \mathrm{~N}\right)_{2} \cdot 2 \mathrm{H}_{2} \mathrm{O}$ nanowires were obtained between ammonium heptamolybdate and aniline. Aniline was used as an intercalating molecule to form one-dimensional $\mathrm{MoO}_{x} /$ amine hybrid structure. The as-synthesized product was characterized by XRD to identify the crystallographic structure and crystallinity, as shown in Fig. 2a. It is ob-
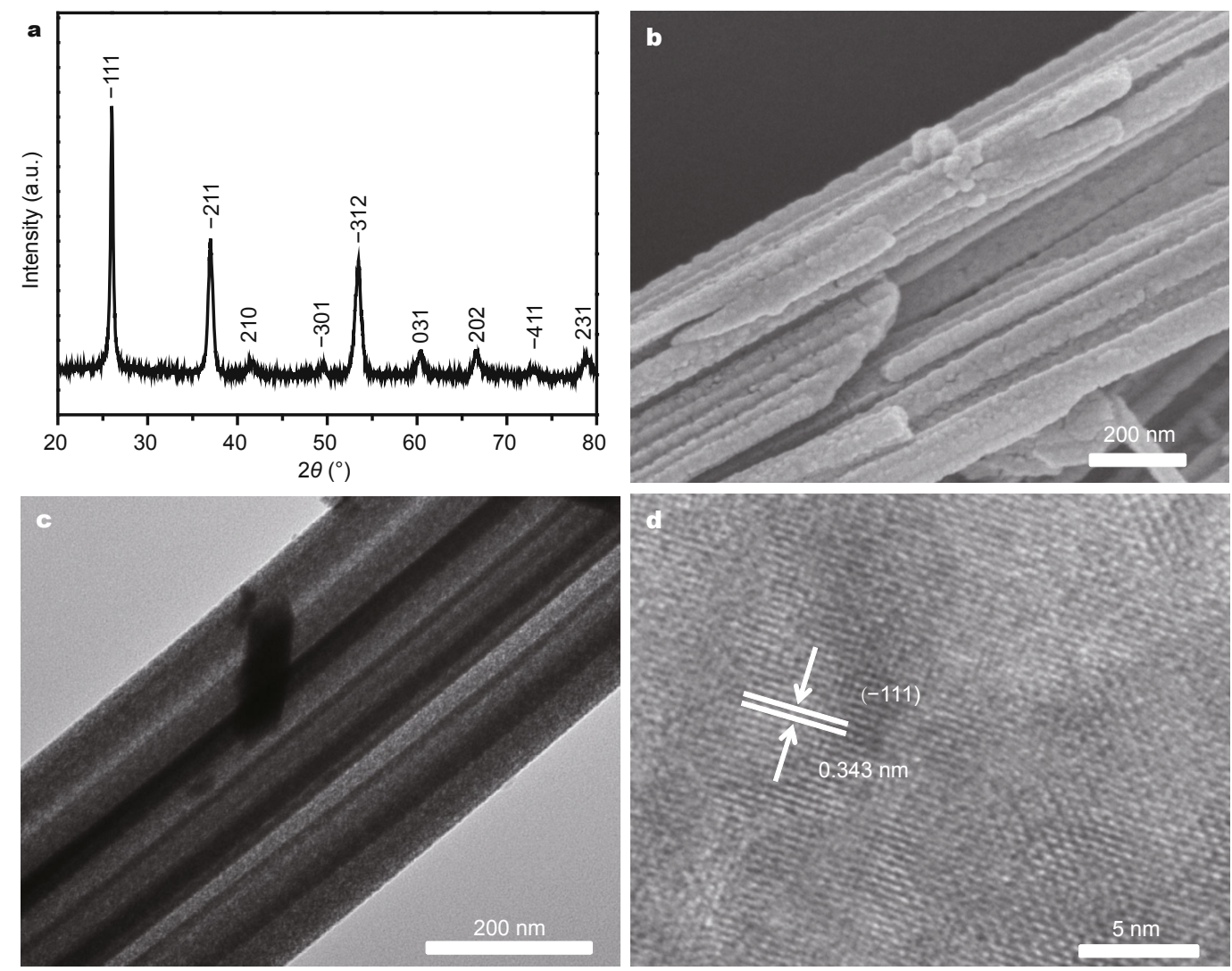

Figure 1 (a) XRD pattern of the $\mathrm{MoO}_{2}$ nanowires. (b) SEM image of the $\mathrm{MoO}_{2}$ nanowires. (c, d) TEM and $\mathrm{HRTEM}$ images of the MoO ${ }_{2}$ nanowires. 

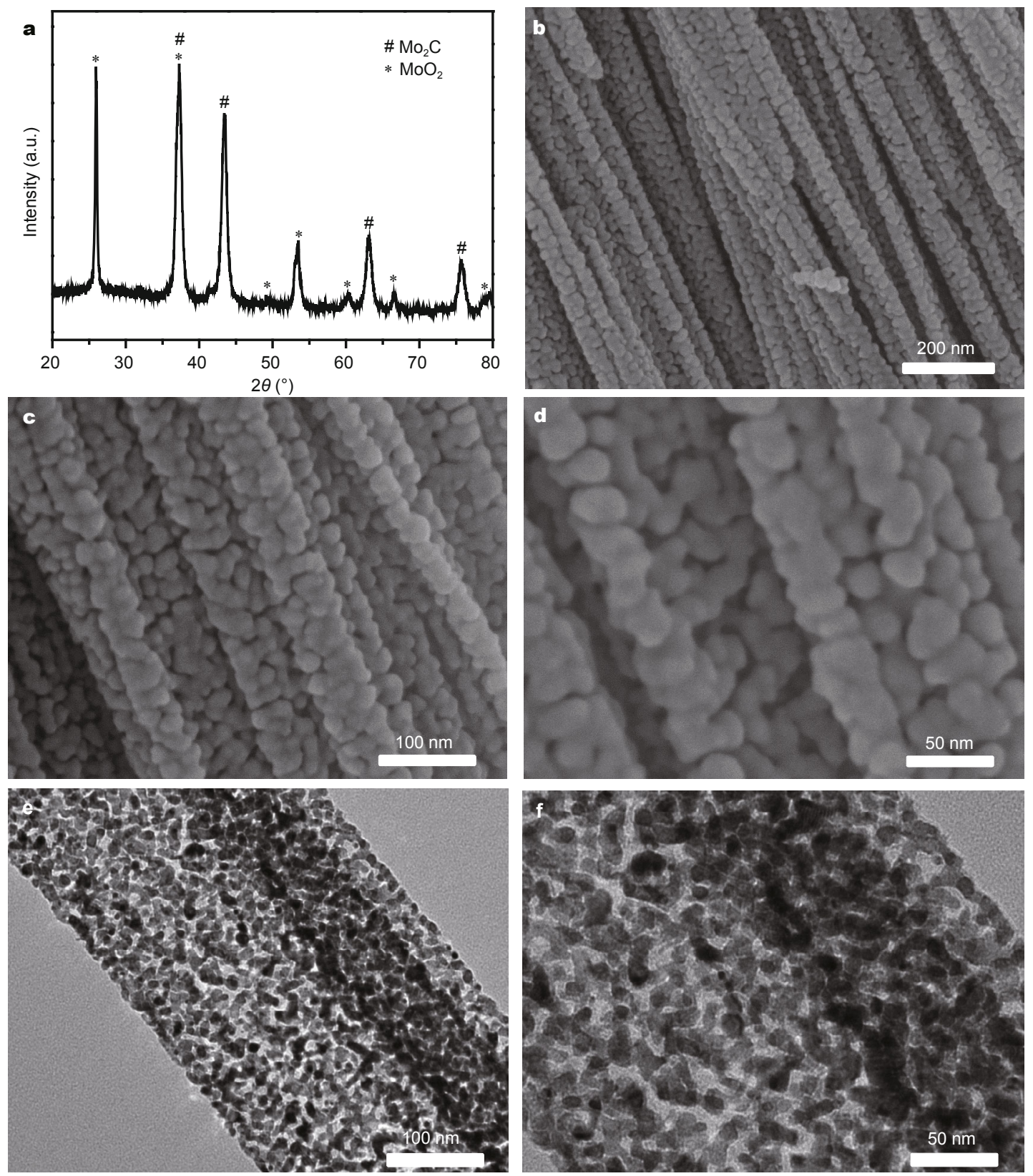

Figure 2 (a) XRD pattern of the porous $\mathrm{Mo}_{2} \mathrm{C} / \mathrm{MoO}_{2}$ heteronanowires. (b-d) SEM images of the porous $\mathrm{Mo}_{2} \mathrm{C} \mathrm{MoO}_{2}$ heteronanowires. (e, f) TEM images of the porous $\mathrm{Mo}_{2} \mathrm{C} / \mathrm{MoO}_{2}$ heterostructures.

served that all of the diffraction peaks can be assigned to the cubic $\mathrm{Mo}_{2} \mathrm{C}$ (JCPDS 15-0457, space group: Fm3m) and monoclinic $\mathrm{MoO}_{2}$ (JCPDS 65-5758, space group: P21/c). The peaks located at $37.5^{\circ}, 53.2^{\circ}, 63.0^{\circ}$ and $75.6^{\circ}$ are ascribed to the (111), (200), (220) and (311) planes of $\mathrm{Mo}_{2} \mathrm{C}$, while the diffraction peaks located at $25.9^{\circ}, 37.2^{\circ}$, and $53.4^{\circ}$ can be assigned to the (011), (200), and (-311) planes of the hexagonal $\mathrm{MoO}_{2}$. No $\mathrm{MoO}_{3}$ or other impurities can be detected, indicating the high purity of the sample. FESEM and TEM were used to examine the morphology of the prepared $\mathrm{Mo}_{2} \mathrm{C} / \mathrm{MoO}_{2}$ heterostructures. As shown in Figs $2 \mathrm{~b}$ and $\mathrm{S} 3$, the low-magnification FESEM image indicates that the obtained samples are highly uniform one-dimensional morphology with a diameter about $100 \mathrm{~nm}$ and a length of several micrometers. The magnified FESEM images (Figs $2 \mathrm{c}$ and $\mathrm{d}$ ) reveal the resultant products are highly porous, which would facilitate the electron transfer and exchange during the catalytic reaction. It can be observed that such 
nanostructure with porous network is composed of numerous irregular particles resulting from the thermal decomposition of organic-inorganic hybrid precursor. TEM further confirms the porous structure of the as-synthesized $\mathrm{Mo}_{2} \mathrm{C} / \mathrm{MoO}_{2}$ heterostructures. As can be seen from Figs $2 \mathrm{e}$, $\mathrm{f}$ and $\mathrm{S} 4$, the samples possess a well-defined porous structure, which are in good agreement with the SEM observation. During thermal decomposition under an inert atmosphere, amine molecules not only act as reducing agent, but also act as carbon resource. Therefore, the formation of porous structure may be associated with the shrinkage of the organic-inorganic hybrid precursor and the generation of $\mathrm{Mo}_{2} \mathrm{C}$ structure. From representative HRTEM images shown in Figs $3 a$ and b, highly crystalline feature can be clearly observed and the interplanar distance between lattice fringes is $0.207 \mathrm{~nm}$, which is consistent with the (200) planes of the $\mathrm{Mo}_{2} \mathrm{C}$ phase. Besides, the interplanar distance between lattice fringes of $0.243 \mathrm{~nm}$ is consistent with the (-112) plane of $\mathrm{MoO}_{2}$ (Fig. 3b). The high-angle annular dark-field scanning TEM (HAADF-STEM) and the corre- sponding energy-dispersive X-ray (EDX) mapping (Figs 3c and d) of $\mathrm{Mo}_{2} \mathrm{C} / \mathrm{MoO}_{2}$ heterostructures show the uniform distribution of molybdenum, carbon and oxygen throughout the whole structure.

The composition and surface chemical state of $\mathrm{Mo}_{2} \mathrm{C} /$ $\mathrm{MoO}_{2}$ heterostructures were also investigated using XPS. The survey spectrum of the sample (Fig. S5a) shows several typical peaks of Mo 3d, Mo 3 $\mathrm{p}_{3 / 2}$, Mo 3 $\mathrm{p}_{1 / 2}$, C 1s, and O 1s. No peaks of other elements are observed on the survey spectrum The corresponding high-resolution XPS spectra (Fig. S5b) show that the peaks at 227.87 and $231.17 \mathrm{eV}$ can be assigned to Mo $3 \mathrm{~d}_{5 / 2}$ and Mo $3 \mathrm{~d}_{3 / 2}$ of $\mathrm{MoO}_{2}$, respectively $[18,42]$. While the peak located at $235.04 \mathrm{eV}$ can be attributed to Mo $3 \mathrm{~d}_{5 / 2}$ of $\mathrm{MoO}_{3}$, which might be ascribed to the surface oxidation of the sample [43]. Fig. S5d shows the XPS spectrum in the $\mathrm{O} 1 \mathrm{~s}$ energy region, which indicates the presence of oxides. Moreover, the corresponding EDS spectrum (Fig. S6) confirms the presence of Mo, O, and C in the product, and the atom ratio of $\mathrm{Mo}$ to $\mathrm{O}$ is far above $1: 2$, indicating that the sample must contain other Mo-ba-
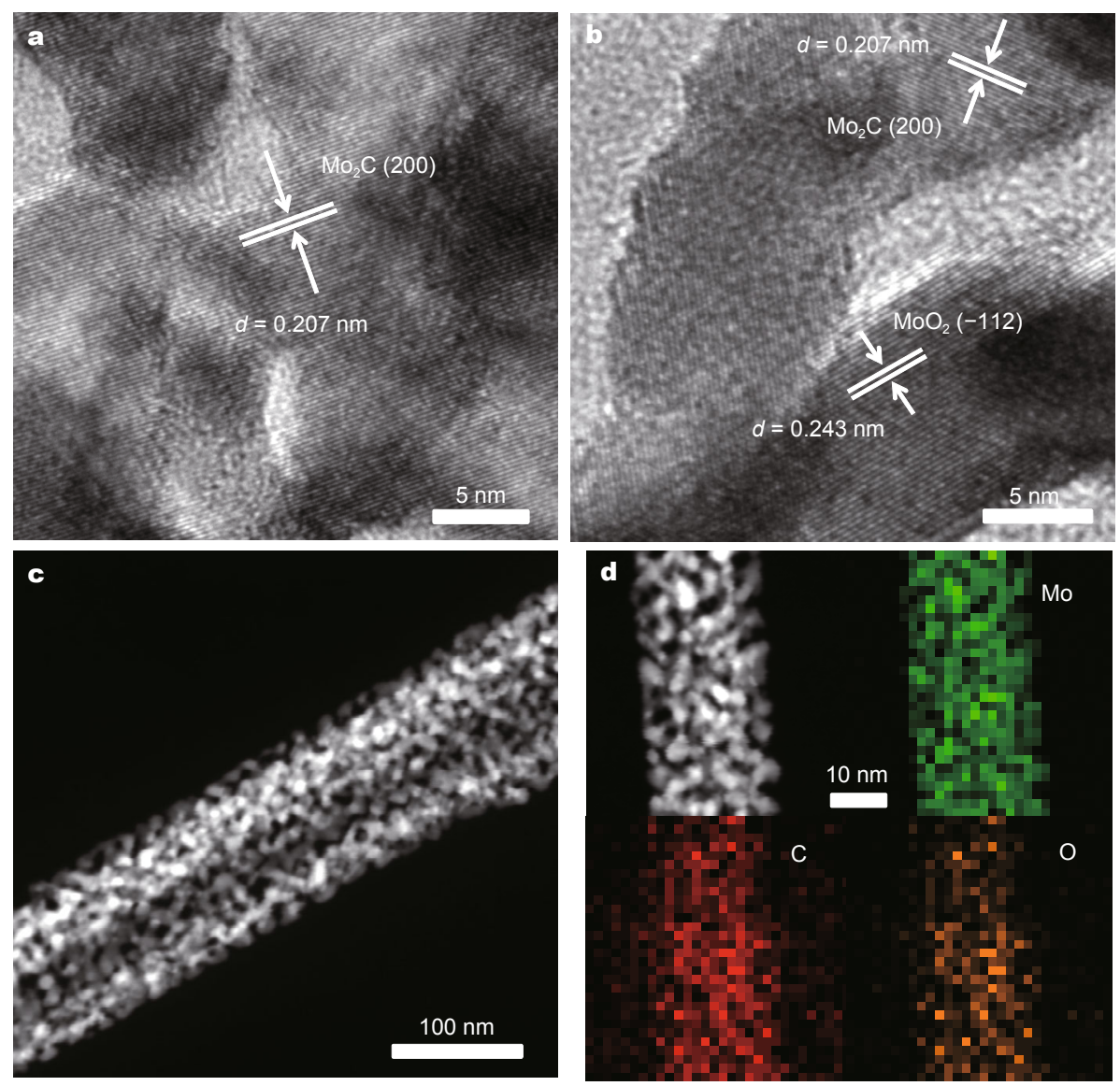

Figure $3(\mathrm{a}, \mathrm{b}) \mathrm{HRTEM}$ images of $\mathrm{Mo}_{2} \mathrm{C} / \mathrm{MoO}_{2}$ heterostructures. (c, d) HAADF-STEM image and the corresponding EDS mapping images, indicating that molybdenum, sulphur, carbon and oxygen are distributed in this architecture. 
sed structure. Based on the results mentioned above, the resulting product is composed of cubic $\mathrm{Mo}_{2} \mathrm{C}$ and hexagonal $\mathrm{MoO}_{2}$

It should be emphasized that the ventilation of $\mathrm{N}_{2}$ flow in advance shows great influences on the final structure and morphology. Fig. S7 shows the XRD patterns of the sample obtained by annealing treatment after expelling air with different time. All of them can be assigned to cubic $\mathrm{Mo}_{2} \mathrm{C}$ and hexagonal $\mathrm{MoO}_{2}$. It is worth noting that increasing the ventilation time with $\mathrm{N}_{2}$ flow leads to an increased intensity for $\mathrm{Mo}_{2} \mathrm{C}$ structure. The corresponding TEM images of the sample were examined in Fig. S8. A lot of nanoparticles can be seen without expelling air. After expelling air by $\mathrm{N}_{2}$ flow for $6 \mathrm{~h}$, we found that these nanoparticles disappeared and porous heterostructures can be obtained. Therefore, ventilation of $\mathrm{N}_{2}$ flow in advance benefits the formation of porous heterostructures. In addition, we also annealed $\mathrm{Mo}_{3} \mathrm{O}_{10}\left(\mathrm{C}_{6} \mathrm{H}_{8} \mathrm{~N}\right)_{2} \cdot 2 \mathrm{H}_{2} \mathrm{O}$ hybrid nanowires under $\mathrm{Ar}-\mathrm{H}_{2}$ flow, and the corresponding XRD result (Fig. S9) shows that the hexagonal phase $\mathrm{Mo}_{2} \mathrm{C}$ nanowires can be obtained. This is in accordance with the previous reports $[24,25]$. These results suggest that the structure and morphology of the final sample have a close relationship with the pretreatment of calcination and annealing atmosphere.
Moreover, we found that ultra-long $\mathrm{MoO}_{3}$ nanowires can be obtained after annealing treatment at $500^{\circ} \mathrm{C}$ in air. The crystallographic structure of the sample is examined by XRD (Fig. 4a). All of the diffraction peaks can be perfectly assigned to orthorhombic $\mathrm{MoO}_{3}$ (JCPDS 35-0609, space group: Pbnm (62)). No other possible impurities such as $\mathrm{MoO}_{2}$ are detected. As shown in Figs $4 \mathrm{~b}$ and c, it is obvious that the products exhibit intact one-dimensional shape with a diameter of about $200 \mathrm{~nm}$ and a length of several micrometers. In agreement with the SEM image, the nanowires structure can be observed from the low-magnification TEM image. The HRTEM image (Fig. 4d) shows that the obvious interplanar distance between lattice fringes is $0.380 \mathrm{~nm}$, which is consistent with the (110) planes of the $\mathrm{MoO}_{3}$ phase. Apparently, this result shows that various Mo-based nanostructures can be obtained by thermal decomposition of organic-inorganic hybrid.

The electrocatalytic activity for HER of the obtained porous $\mathrm{Mo}_{2} \mathrm{C} / \mathrm{MoO}_{2}$ sample was further studied by electrochemical measurements in $0.5 \mathrm{~mol} \mathrm{~L}^{-1} \mathrm{H}_{2} \mathrm{SO}_{4}$ using a rotating disc electrode (RDE) in a typical three-electrode setup on a glassy carbon electrode. For comparison, the HER catalytic activity of the commercial $\mathrm{Mo}_{2} \mathrm{C}$, the as-obtained $\mathrm{MoO}_{2}$ nanowires, $\mathrm{MoO}_{3}$ nanowires and $\mathrm{Pt}-\mathrm{C}$ was also in-
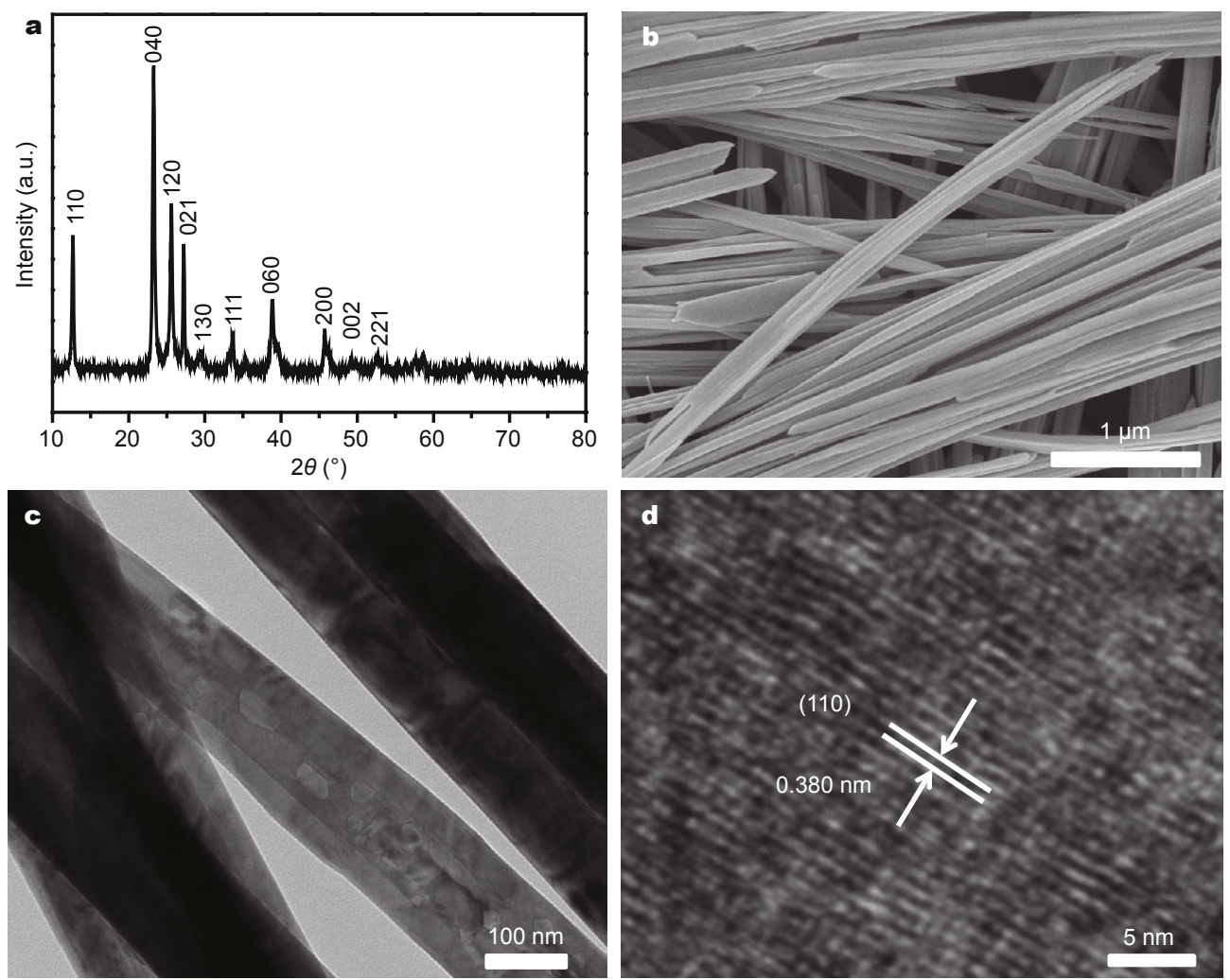

Figure 4 (a) XRD pattern of the $\mathrm{MoO}_{3}$ nanowires. (b, c) SEM and TEM images of the $\mathrm{MoO}_{3}$ nanowires. (d) $\mathrm{HRTEM}$ image of the $\mathrm{MoO}_{3}$ nanowires 
vestigated. As shown in Fig. 5a, the polarization curves of porous $\mathrm{Mo}_{2} \mathrm{C} / \mathrm{MoO}_{2}$ heteronanowires ( $I-V$ plot, iR corrected) exhibit a small overpotential of $-0.19 \mathrm{~V}$. And the overpotential is about $315 \mathrm{mV} v s$. RHE at an HER current of $10 \mathrm{~mA} \mathrm{~cm}^{-2}$. In sharp contrast, the commercial $\mathrm{Mo}_{2} \mathrm{C}$, $\mathrm{MoO}_{2}$ nanowires and $\mathrm{MoO}_{3}$ nanowires exhibit poor HER activity, and no reduction current can be seen until the electrode potential over $-0.4 \mathrm{~V}$.

The Tafel slopes were further evaluated the intrinsic activity of all samples. It is generally acknowledged that three principle steps for the conversion of $\mathrm{H}^{+}$to $\mathrm{H}_{2}$ have been suggested for the HER in acidic media as below [24]:

Volmer step: $\mathrm{H}^{+}+\mathrm{e}^{-1} \rightarrow \mathrm{H}_{\text {ads }}$, (Tafel slope: $\sim 120 \mathrm{mV}$ )

Heyrovsky step: $\mathrm{H}_{\mathrm{ads}}+\mathrm{H}^{+}+\mathrm{e}^{-1} \rightarrow \mathrm{H}_{2}$, (Tafel slope: $\sim 40 \mathrm{mV}$ ) Tafel step: $\mathrm{H}_{\mathrm{ads}}+\mathrm{H}_{\mathrm{ads}} \rightarrow \mathrm{H}_{2}$. (Tafel slope: $\sim 30 \mathrm{mV}$ )

The linear portions of the Tafel plots (Fig. 5b) were fit to the Tafel equation $(\eta=b \log j+a$, where $b$ is the Tafel slope) $[44,45]$. And the corresponding Tafel slops are $~ 30, \sim 94$ and $\sim 329 \mathrm{mV}$ for Pt-C, as-obtained $\mathrm{Mo}_{2} \mathrm{C} / \mathrm{MoO}_{2}$ heteronanowires and commercial $\mathrm{Mo}_{2} \mathrm{C}$, respectively. Such Tafel slope of
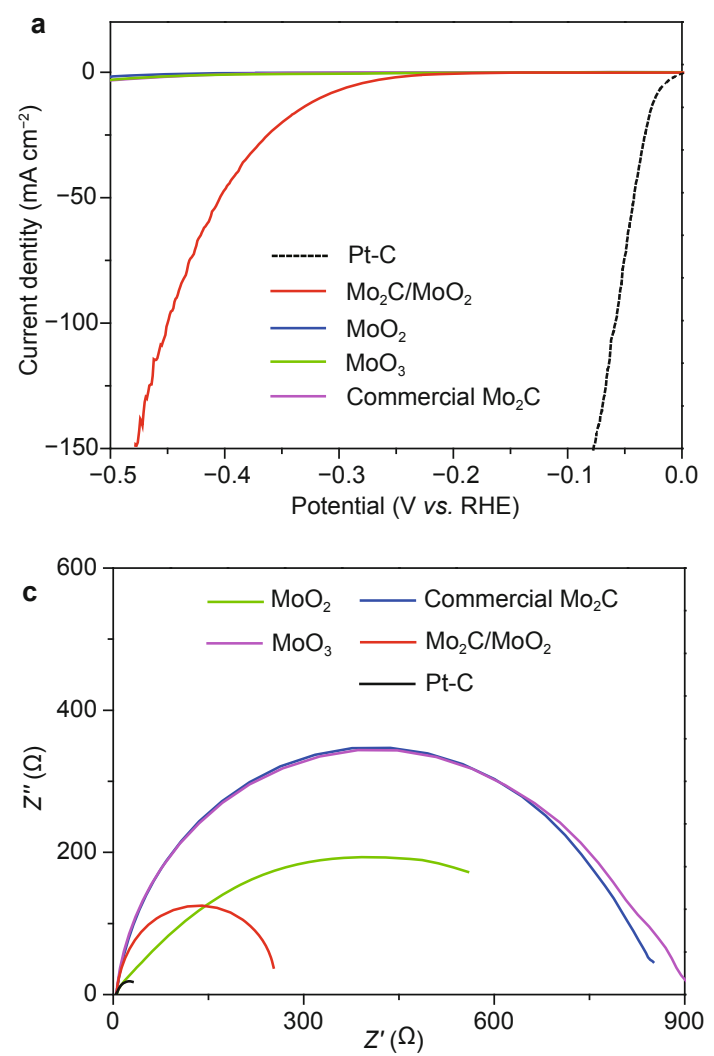

$94 \mathrm{mV}$ per decade means that the porous $\mathrm{Mo}_{2} \mathrm{C} / \mathrm{MoO}_{2}$ heteronanowires follow a mechanism of Volmer-Heyrovsky combination process, and desorption step is the rate-determining step for HER [46]. While the Pt-C electrode with a small Tafel slope of $30 \mathrm{mV}$ per decade belongs to Tafel step and the chemical recombination of $\mathrm{H}_{\mathrm{ads}}$ is the rate-determining step $[45,47]$. In addition, EIS was also used to characterize the interfacial reactions and electron-transfer kinetics in HER. Fig. $5 c$ shows the representative Nyquist plots of all samples. The $\mathrm{Mo}_{2} \mathrm{C} / \mathrm{MoO}_{2}$ heteronanowires exhibited much lower charge transfer impedance of $\sim 270 \Omega$ than commercial $\mathrm{Mo}_{2} \mathrm{C}(\sim 850 \Omega)$ and $\mathrm{MoO}_{3}(\sim 900 \Omega)$, indicating faster interfacial reactions during HER process, which is consistent with the polarization measurements. The stability of the $\mathrm{Mo}_{2} \mathrm{C} / \mathrm{MoO}_{2}$ heterostructures were further evaluated through the accelerated durability tests by cycling the electrode at a scan rate of $100 \mathrm{mV} \mathrm{s}^{-1}$. As shown in Fig. 5d, the performance of the $\mathrm{Mo}_{2} \mathrm{C} / \mathrm{MoO}_{2}$ heterostructures after 4000 cycles showed no degradation compared with the fresh electrode. The performance of $\mathrm{Mo}_{2} \mathrm{C} / \mathrm{MoO}_{2}$ heterostructures displays an increasing trend.
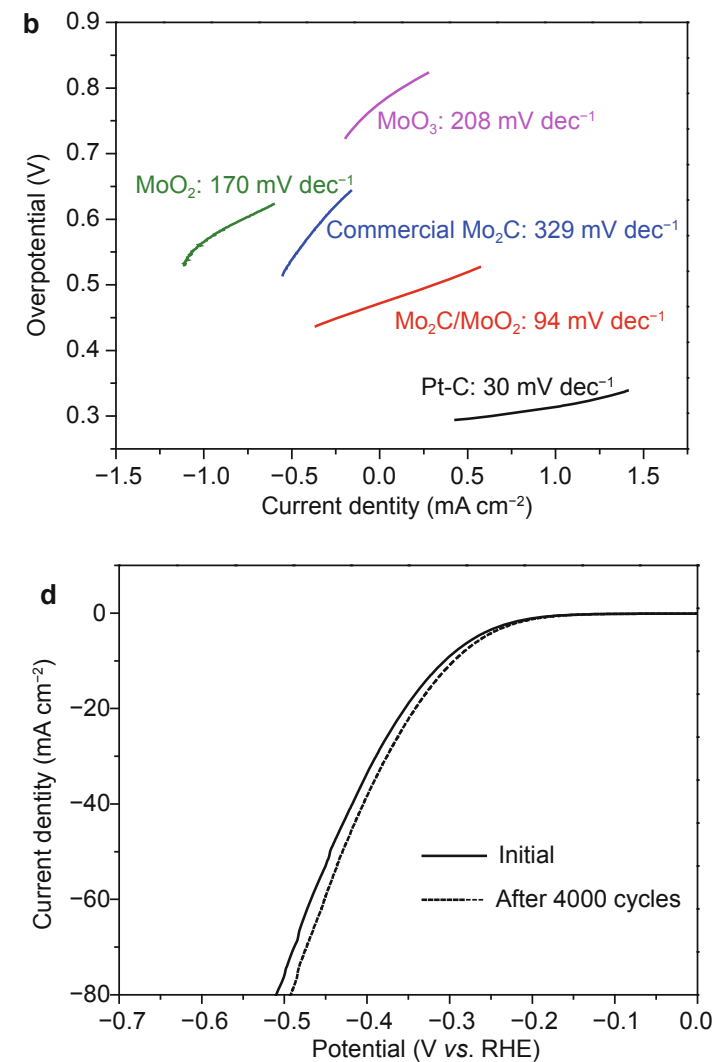

Figure 5 (a) Polarization curves and (b) corresponding Tafel plots of the $\mathrm{Mo}_{2} \mathrm{C} / \mathrm{MoO}_{2}$ heteronanowires along with the as-obtained $\mathrm{MoO}$ nanowires, $\mathrm{MoO}_{3}$ nanowires, commercial $\mathrm{Mo}_{2} \mathrm{C}$ and $\mathrm{Pt} / \mathrm{C}$ for comparison. (c) Nyquist plots of the $\mathrm{Mo}_{2} \mathrm{C}_{2} \mathrm{MoO}_{2}$ heteronanowires, the as-obtained $\mathrm{MoO}$ nanowires, $\mathrm{MoO}_{3}$ nanowires, commercial $\mathrm{Mo}_{2} \mathrm{C}$ and $\mathrm{Pt} / \mathrm{C}$. (d) Durability test for the $\mathrm{Mo}_{2} \mathrm{C} / \mathrm{MoO}_{2}$ heteronanowires after $4000 \mathrm{CV}$ cycles at a scan rate of $100 \mathrm{mV} \mathrm{s}{ }^{-1}$ between -0.6 and $-0.2 \mathrm{~V}$ vs. SCE. 
This increase is likely associated with a gradual activation of the electrode materials. In addtion, the electrochemical inactive $\mathrm{Mo}_{2} \mathrm{C}$ nanostructure is also responsible for the structural stability, leading to a good cycling performance in acidic media.

The improved HER performance of the porous $\mathrm{Mo}_{2} \mathrm{C} /$ $\mathrm{MoO}_{2}$ heterostructures might be mainly ascribed to their unique structure. First, enriched porous structure would effectively facilitate the transport of electrons or protons during the catalytic reaction. As determined by nitrogen adsorption-desorption isotherms (Fig. S10), such a unique structure gives rise to BET surface area of $55.26 \mathrm{~m}^{2} \mathrm{~g}^{-1}$ and a relatively high pore volume of $0.249 \mathrm{~cm}^{3} \mathrm{~g}^{-1}$. Second, the existence of $\mathrm{Mo}_{2} \mathrm{C}$ with a high electrical conductivity not only decreases the resistance of the sample, but also improves the structural stability of the heteronanowires. It is believed that the HER activity of such porous $\mathrm{Mo}_{2} \mathrm{C} / \mathrm{MoO}_{2}$ heterostructures could be further improved by decorating with graphene. As a result, the porous $\mathrm{Mo}_{2} \mathrm{C} / \mathrm{MoO}_{2}$ heteronanowires can be used as a promising material for HER catalyst.

\section{CONCLUSION}

In summary, we have demonstrated a facile strategy to synthesize Mo-based nanostructures through calcination treatment of $\mathrm{MoO}_{x}$-based organic-inorganic hybrid precursor. Well-defined Mo-based nanostructures, including one-dimensional $\mathrm{MoO}_{2}$ and $\mathrm{MoO}_{3}$ nanowires, can be prepared in large quantities by changing the hybrid precursor under an inert atmosphere. What is more, a network of interconnected $\mathrm{Mo}_{2} \mathrm{C} / \mathrm{MoO}_{2}$ heterostructures was successfully synthesized after thermal decomposition. The resultant $\mathrm{Mo}_{2} \mathrm{C} / \mathrm{MoO}_{2}$ heteronanowires possess highly crystalline, enriched porous structure and large surface areas. When evaluated as a catalyst towards HER, the resultant material shows good active and stable catalysts in acidic electrolytes. The improved HER catalytic effects of porous $\mathrm{Mo}_{2} \mathrm{C} / \mathrm{MoO}_{2}$ heterostructures can be ascribed to the high electrical conductivity of $\mathrm{Mo}_{2} \mathrm{C}$ and porous structures. Taking the facile fabrication method and excellent electrochemical performance into consideration, it is believed that the present work described here presents a way to fabricate other Mobased nanostructures for various applications.

Received 7 September, 2015; accepted 28 September 2015; published online 16 October 2015

1 Yang $\mathrm{H}$, Sun $\mathrm{C}$, Qiao S, et al. Anatase $\mathrm{TiO}_{2}$ single crystals with a large percentage of reactive facets. Nature, 2008, 453: 638-641

2 Shi Y, Guo B, Corr SA, et al. Ordered mesoporous metallic $\mathrm{MoO}_{2}$ materials with highly reversible lithium storage capacity. Nano Lett, 2009, 9: 4215-4220
3 Hercule KM, Wei Q, Khan AM, et al. Synergistic effect of hierarchical nanostructured $\mathrm{MoO}_{2} / \mathrm{Co}(\mathrm{OH})_{2}$ with largely enhanced pseudocapacitor cyclability. Nano Lett, 2013, 13: 5685-5691

4 Gao M, Chan M, Sun Y. Edge-terminated molybdenum disulfide with a 9.4- $\AA$ interlayer spacing for electrochemical hydrogen production. Nat Commun, 2015, 6: 7493-7501

5 Wen X, Yang W, Ding Y, et al. Piezoresistive effect in $\mathrm{MoO}_{3}$ nanobelts and its application in strain-enhanced oxygen sensors. Nano Res, 2014, 7: 180-189

6 Buscnma M, Steele GA, van der Zant HSJ, et al. The effect of the substrate on the Raman and photoluminescence emission of single-layer $\mathrm{MoS}_{2}$. Nano Res, 2014, 7: 561-567

7 Gastellanos-Gomez A, van der Zant HSJ, Steele GA. Folded $\mathrm{MoS}_{2}$ layers with reduced interlayer coupling. Nano Res, 2014, 7: 572-578

8 Sun Y, Hu X, Luo W, Huang Y. Self-assembled hierarchical $\mathrm{MoO}_{2} /$ graphene nanoarchitectures and their application as a high-performance anode material for lithium-ion battery. ACS Nano, 2011, 5: 7100-7107

$9 \mathrm{Hu}$ B, Mai L, Chen W, et al. From $\mathrm{MoO}_{3}$ nanobelts to $\mathrm{MoO}_{2}$ nanorods: structure transformation and electrical transport. ACS Nano, 2009, 3: 478-482

10 Walter MG, Warren EL, McKone JR, et al. Solar water splitting cells. Chem Rev, 2010, 110: 6446-6473

11 Dempsey JL, Brunschwig BS, Winkler JR, Gray HB. Hydrogen evolution catalyzed by cobaloximes. Acc Chem Res, 2009, 42: 19952004

12 Hao R, Jiang B, Li M, et al. Fabrication of mixed-crystalline-phase spindle-like $\mathrm{TiO}_{2}$ for enhanced photocatalytic hydrogen production. Sci China Mater, 2015, 58: 363-369

13 Yin Y, Zhao S, Zhao K, et al. Ultrathin platinum nanowires grown on single-layered nickel hydroxide with high hydrogen evolution activity. Nat Commun, 2015, 6: 6430-6438

14 Millet P, Andolfatto F, Durand R. Design and performance of a solid polymer electrolyte water electrolyzer. Int J Hydrogen Energy, 1996, 21: 87-93

15 Benck JD, Chen Z, Kuritzky LY, et al. Amorphous molybdenum sulfide catalysts for electrochemical hydrogen production: insights into the origin of their catalytic activity. ACS Catal, 2012, 2: 19161923

16 Xie J, Zhang J, Li S, et al. Controllable disorder engineering in oxygen-incorporated $\mathrm{MoS}_{2}$ ultrathin nanosheets for efficient hydrogen evolution. J Am Chem Soc, 2013, 135: 17881-17888

17 Yang Y, Wang S, Zhang J, et al. Nanosheet-assembled $\mathrm{MoSe}_{2}$ and $\mathrm{S}$-doped $\mathrm{MoSe}_{2-x}$ nanostructures for superior lithium storage properties and hydrogen evolution reactions. Inorg Chem Front, 2015, 2: 931-937

18 Gao Q, Zhao X, Xiao Y, et al. A mild route to mesoporous $\mathrm{Mo}_{2} \mathrm{C}-\mathrm{C}$ hybrid nanospheres for high performance lithium-ion batteries. Nanoscale, 2014, 6: 6151-6157

19 Liang CH, Ying PL, Li C. Nanostructured $\beta-\mathrm{Mo}_{2} \mathrm{C}$ prepared by carbothermal hydrogen reduction on ultrahigh surface area carbon material. Chem Mater, 2002, 14: 3148-3151

20 Kolel-Veetil MK, Qadri SB, Osofsky M, et al. Formation of a superconducting mixture of $\beta-\mathrm{Mo}_{2} \mathrm{C}$ nanoparticles and carbon nanotubes in an amorphous matrix of molybdenum compounds by the pyrolysis of a molybdenum derivative of a carboranylenesiloxane. Chem Mater, 2005, 17: 6101-6107

21 Lunkenbein T, Rosenthal D, Otremba T, et al. Access to ordered porous molybdenum oxycarbide/carbon nanocomposites. Angew Chem Int Ed, 2012, 51: 12892-12896

22 Wolden CA, Pickerell A, Gawai T, et al. Synthesis of $\beta-\mathrm{Mo}_{2} \mathrm{C}$ thin films. ACS Appl Mater Interfaces, 2011, 3: 517-521

23 Pang $\mathrm{M}$, Chen $\mathrm{X}, \mathrm{Xu} \mathrm{Q} . \mathrm{MoC}_{x}$ species embedded in ordered mes- 
oporous silica framework with hierarchical structure for hydrogenation of naphthalene. Applied Catalysis A General, 2015, 490: 146-152

24 Xing Z, Liu Q, Asiri AM, Sun X. Closely interconnected network of molybdenum phosphide nanoparticles: a highly efficient electrocatalyst for generating hydrogen from water. Adv Mater, 2014, 26 5702-5707

25 Liao L, Wang S, Xiao J, et al. A nanoporous molybdenum carbide nanowire as an electrocatalyst for hydrogen evolution reaction. Energy Environ Sci, 2014, 7: 387-392

26 Gao Q, Zhang C, Xie S, et al. Synthesis of nanoporous molybdenum carbide nanowires based on organic-inorganic hybrid nanocomposites with sub-nanometer periodic structures. Chem Mater, 2009, 21: 5560-5562

27 Chen WF, Wang $\mathrm{CH}$, Sasaki K, et al. Highly active and durable nanostructured molybdenum carbide electrocatalysts for hydrogen production. Energy Environ Sci, 2013, 6: 943-951

28 Li D, Zhang Y, Li L, et al. Polydopamine directed MnO@C microstructures as electrode for lithium ion battery. Sci China Chem, 2015, doi: 10.1007/s11426-015-5439-1

29 Jin Q, Pei L, Hu Y, et al. Solvo/hydrothermal preparation of $\mathrm{MnO}_{x} @$ rGO nanocomposites for electrocatalytic oxygen reduction. Acta Chim Sinica, 2014, 72: 920-926

30 Zhao D, Li Z, Liu L, et al. Progress of preparation and application of graphene/carbon nanotube composite materials. Acta Chim Sinica, 2014, 72: 185-200

31 Wang X, Li B, Liu D, et al. $\mathrm{ZnWO}_{4}$ nanocrystals/reduced graphene oxide hybrids: synthesis and their application for $\mathrm{Li}$ ion batteries. Sci China Chem, 2014, 57: 185-200

32 Ni JF, Zhao Y, Li L, Mai L. Ultrathin $\mathrm{MoO}_{2}$ nanosheets for superior lithium storage. Nano Energy, 2015, 11: 122-126

33 Wu L, Wang X, Sun Y, et al. Flawed $\mathrm{MoO}_{2}$ belts transformed from $\mathrm{MoO}_{3}$ on a graphene template for the hydrogen evolution reaction. Nanoscale, 2015, 7: 7040-7044

34 Mokari T, Rothenberg E, Popov I, et al. Selective growth of metal tips onto semiconductor quantum rods and tetrapods. Science, 2004, 304: 1787-1790

35 Peng S, Li L, Han X, et al. Cobalt sulfide nanosheet/graphene/carbon nanotube nanocomposites as flexible electrodes for hydrogen evolution. Angew Chem Int Ed, 2014, 53: 12594-12599

36 Wang RH, Yang J, Shi KY, et al. Single-step pyrolytic preparation of $\mathrm{Mo}_{2} \mathrm{C} /$ graphitic carbon nanocomposite as catalyst carrier for the direct liquid-feed fuel cells. RSC Adv, 2013, 3: 4771-4777

37 Pang M, Li C, Ding L, et al. Microwave-assisted preparation of $\mathrm{Mo}_{2} \mathrm{C} / \mathrm{CNT}$ nanocomposites as efficient electrocatalyst supports for oxygen reduction reaction. Ind Eng Chem Res, 2010, 49: 4169-
4174

38 Yang $\mathrm{Y}$, Zhang $\mathrm{Z}$, Wang $\mathrm{P}$, et al. Hierarchical $\mathrm{MnO}_{2} / \mathrm{SnO}_{2}$ heterostructures for a novel free-standing ternary thermite membrane. Inorg Chem, 2013, 52: 9449-9455

$39 \mathrm{Xu} \mathrm{B}$, Yang H, Zhou G, Wang X. Strong metal-support interaction in size-controlled monodisperse palladium-hematite nanoheterostructures during a liquid-solid heterogeneous catalysis. Sci China Mater, 2014, 57: 34-41

40 Zhang $\mathrm{H}$, Wang $\mathrm{K}$, Wu X, et al. $\mathrm{MoO}_{2} / \mathrm{Mo}_{2} \mathrm{C}$ heteronanotubes function as high-performance Li-ion battery electrode. Adv Funct Mater, 2014, 24: 3399-2404

41 Gao Q, Wang S, Fang $\mathrm{H}$, et al. One-dimensional growth of $\mathrm{MoO}_{x}$ based organic-inorganic hybrid nanowires with tunable photochromic properties. J Mater Chem, 2012, 22: 4709-4715

42 Lin YC, Zhang W, Huang JK, et al. Wafer-scale $\mathrm{MoS}_{2}$ thin layers prepared by $\mathrm{MoO}_{3}$ sulfurization. Nanoscale, 2012, 4: 6637-6641

43 Sen UK, Shaligram A, Mitra S. Intercalation anode material for lithium ion battery based on molybdenum dioxide. ACS Appl Mat Interfaces, 2014, 6: 14311-14319

44 Vrubel H, Merki D, Hu X. Hydrogen evolution catalyzed by $\mathrm{MoS}_{3}$ and $\mathrm{MoS}_{2}$ particles. Energy Environ Sci, 2012, 5: 6136-6144

45 Li Y, Wang H, Xie L, et al. $\mathrm{MoS}_{2}$ nanoparticles grown on graphene: an advanced catalyst for the hydrogen evolution reaction. J Am Chem Soc, 2011, 133: 7296-7299

46 Liao L, Zhu J, Bian X, et al. $\mathrm{MoS}_{2}$ formed on mesoporous graphene as a highly active catalyst for hydrogen evolution. Adv Funct Mater, 2013, 23: 5326-5333

47 Dempsey JL, Brunschwig BS, Winkler JR, Gray HB. Hydrogen evolution catalyzed by cobaloximes. Acc Chem Res, 2009, 42: 1995-2004

Acknowledgements This work was supported by the National Natural Science Foundation of China (91127040 and 21221062), and the State Key Project of Fundamental Research for Nanoscience and Nanotechnology (2011CB932402).

Author contributions Yang Y designed and performed the synthesis and characterizations, and wrote this manuscript; $\mathrm{Xu} X$ provided valuable discussion on experimental results; Wang $\mathrm{X}$ supervised the experimental work. All authors contributed to the general discussion and wrote the manuscript together.

Conflict of interest The authors declare that they have no conflict of interest.

Supplementary information Supporting data are available in the online version of the paper. 


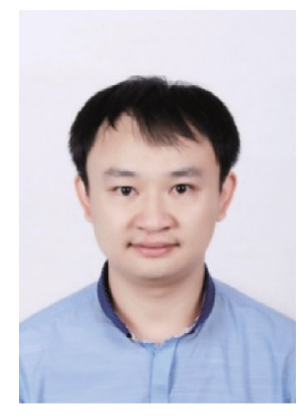

Yang Yong was born in 1987. He received his BSc and MSc degrees from the College of Chemical Engineering, Northwest University in 2009 and 2012, respectively. His research interests are focused on the design and synthesis of Mo-based nanostructures for energy related applications.

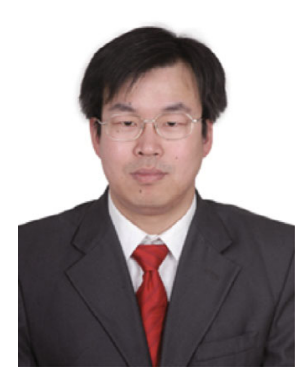

Wang Xun is currently a professor at the Department of Chemistry, Tsinghua University, Beijing, China. He got his $\mathrm{PhD}$ degree in Chemistry from the Department of Chemistry, Tsinghua University in 2004. His research interests focus on the synthesis, assembly, characterization and application of ultrathin nanomaterials.

中文摘要 钼基纳米材料因其特殊的结构和良好的化学性质被广泛应用于传感器和催化领域. 其中, 碳化钼具有类似贵金属的电子结 构和催化特性, 受到了越来越多的关注. 在本研究工作中, 通过对有机-无机复合材料在惰性气氛下进行热处理, 制备了不同的一维钼氧 化物纳米材料以及碳化钼/氧化钼多孔异质纳米材料. 析氢电催化性能表明碳化钼/氧化钼多孔异质材料显示出优异的析氢性能和循环 稳定性. 此方法制备过程简单有效且适合大量制备, 同时为制备新型钼基纳米材料提供了新的思路. 